\title{
RISCO DE INFECÇÃO PELO HIV: COMO MULHERES MORADORAS EM UMA FAVELA SE PERCEBEM NA CADEIA DE TRANSMISSÃo do VÍRUS ${ }^{1}$
}

\author{
Neide de Souza Praça² \\ Dulce Maria Rosa Gualda ${ }^{3}$
}

Praça NS, Gualda DMR. Risco de infecção pelo HIV: como mulheres moradoras em uma favela se percebem na cadeia de transmissão do vírus. Rev Latino-am Enfermagem 2003 janeiro-fevereiro; 11(1):14-20.

O número de casos notificados de AIDS em mulheres, no Brasil, continua em progressão. Esse fato motivou a realização deste estudo que foi desenvolvido com abordagem qualitativa, tendo como referencial teórico a Antropologia Cultural e o método etnográfico para a coleta e a análise dos dados. Objetivou identificar a percepção de risco de infecção pelo HIV, de mulheres moradoras em uma favela localizada na cidade de São Paulo, Brasil. Constou de entrevistas e de observação participante do contexto. Os resultados mostraram que essas mulheres demonstram conhecimentos sobre AIDS e reconhecem as várias formas de transmissão do HIV, bem como medidas de prevenção pela via sexual. Verificou-se, também, que essas mulheres não se vêem suscetíveis à infecção pelo HIV, por meio de seus parceiros, dependendo deles para se manterem saudáveis, bem com a sua família. Essa maneira de pensar e de agir pode estar contribuindo para a heterossexualização da AIDS no país.

DESCRITORES: saúde da mulher, síndrome de imunodeficiência adquirida, cuidados de enfermagem

\section{THE RISK OF HIV INFECTION: PERCEPTION OF WOMEN LIVING IN A SLUM ABOUT THEIR PARTICIPATION IN THE VIRUS TRANSMISSION CHAIR}

The number of notified cases of women with AIDS is increasing in Brazil. Based on this, the authors developed this qualitative study theoretically based on Cultural Anthropology. The ethnographic methodology was used to collect and to analyze data. The investigation had the purpose to identify the perception about the risk for HIV infection of the women living in a slum located in the city of São Paulo, Brazil, through interviews and participant observation of the context. Results showed that the women have some knowledge about AIDS, about the transmission of HIV and its preventive measures through sexual intercourse. The cultural data also showed that the women do not feel susceptible to the disease, although most of them are dependent on their partners' income to maintain themselves healthy as well as their families. This way of thinking and acting may be contributing to increase the cases of women with AIDS in Brazil.

DESCRIPTORS: women's health, acquired immunodeficiency syndrome, nursing care

\section{RIESGO DE INFECCIÓN POR EL HIV: COMO MUJERES MORADORAS EN UN ASENTAMIENTO HUMANO SE PERCIBEN EN LA CADENA DE TRANSMISIÓN DEL VIRUS}

Los datos epidemiológicos vienen demostrando progreso en el número de casos notificados de SIDA en mujeres, en Brasil. Este hecho motivó la realización del presente estudio desarrollado con abordaje cualitativo, teniendo como referencial la Antropología Cultural y el método etnográfico para la recolección y análisis de los datos. Buscó identificar la percepción de riesgo de infección por el HIV de mujeres moradoras en un asentamiento humano localizado en la ciudad de São Paulo. Constó de entrevistas y de observación participante del contexto, en el período de 1995 a 1998. Los resultados mostraron que las mujeres de esta comunidad demuestran conocimientos sobre SIDA y reconocen las diversas formas de transmisión del HIV, así como el medio de prevención por la vía sexual. El análisis de los datos culturales mostró que estas mujeres no se ven susceptibles a la infección por el HIV a través de su pareja, no obstante, dependen de ellos para mantenerse saludables tanto ellas como su familia. Esta manera de pensar y de actuar puede estar contribuyendo a la heterosexualización del SIDA en el país.

DESCRIPTORES: salud de la mujer, síndrome de inmunodeficiencia adquirida, atención de enfermería

\footnotetext{
${ }^{1}$ Texto extraído da Tese de Doutorado "A cuidadora e o (ser)cuidado: uma relação de dependência no enfrentamento da AIDS" apresentada à Escola de Enfermagem da Universidade de São Paulo. Texto apresentado no XII Congresso Latino-Americano de DST e VI Conferência PanAmericana de AIDS (1999); ${ }^{2}$ Enfermeira obstétrica. Professor Doutor, e-mail: ndspraca@usp.br; ${ }^{3}$ Obstetriz. Professor Associado. Escola de Enfermagem da Universidade de São Paulo
} 
As mulheres, principalmente aquelas com

Os dados epidemiológicos vêm demonstrando progressão no número de casos notificados de AIDS em mulheres, no Brasil. Esse aumento caracteriza a participação da população heterossexual, envolvendo mulheres em idade reprodutiva, especialmente jovens ${ }^{(1)}$.

Um fator de relevância no perfil dos indivíduos infectados pelo HIV e vítimas da AIDS reside no elevado número de morte de mulheres por AIDS, no Município de São Paulo, no período de 1991 a 1993, quando 75\% tiveram essa causa. Os autores sugerem que as donas de casa são as mais atingidas. Referem, também, que $45 \%$ das mulheres com AIDS, em São Paulo, têm parceiros exclusivos $^{(2)}$.

Ao analisar os dados epidemiológicos brasileiros referentes ao período de 1983 a 2001, verifica-se que o maior número de casos notificados de AIDS em mulheres teve a via sexual como categoria de exposição, sendo a maior representação para o contato heterossexual (55,9\% do total de casos de mulheres notificados), seguida por mulheres usuárias de drogas injetáveis (14,4\%). Identificase na mesma fonte que a transmissão perinatal é de $80,8 \%$ do total de casos notificados para ambos os sexos, em menores de 13 anos $^{(3)}$.

A par dessa situação, estão as dificuldades da mulher em encontrar respaldo social para interpelar os maridos sobre questões referentes à segurança e à saúde ${ }^{(4)}$. A autora exemplifica essa condição, citando o resultado de um estudo que realizou na cidade do Rio de Janeiro, com mulheres HIV positivas ou soronegativas, parceiras sexuais de homens soropositivos para o vírus. Identificou uma não abordagem dessas mulheres junto a seus parceiros, mesmo entre aquelas que possuíam informações básicas sobre as vias de transmissão do HIV e reconheciam que seus companheiros freqüentemente se expunham a situações de risco para o vírus.

Esse aparente desinteresse das mulheres pela preservação de sua saúde é justificado pela característica da cultura sexual brasileira que considera diferentemente a natureza do homem e da mulher ${ }^{(2)}$. Os autores afirmam que, nesse aspecto, a mulher sente-se submetida à impetuosidade, ao gosto pela aventura e ao prazer e à objetividade masculinos. A sensibilidade feminina, por outro lado, constitui-se em fator afetivo que se caracteriza pela passividade e pela paciência ${ }^{(2-4)}$. parceiros exclusivos, por não poderem dialogar com eles sobre medidas de sexo mais seguro, submetem-se à sua vontade quanto ao não uso do preservativo; tornam-se, assim, mais vulneráveis à infecção pelo HIV e outras doenças sexualmente transmissíveis, pois seus companheiros, com freqüência, têm mais parceiras fora da relação, sem que suas esposas tomem conhecimento do fato. Na visão dos autores, essa situação traz implicações sociais sérias que demandam alterações no comportamento dos envolvidos, os quais precisam dialogar a respeito de sua sexualidade para melhor se protegerem $^{(5)}$.

O "padrão sexual" brasileiro, que expõe a mulher a riscos de infecção pelo HIV, explica o fato de que, na maioria das vezes, a mulher nem percebe sua exposição. Nossa sociedade aceita melhor as "relações ocasionais ou extraconjugais" dos homens do que das mulheres. As medidas preventivas de infecção pelo HIV devem priorizar as mulheres com relações conjugais em que a exclusividade dos parceiros deve atender às normas do casamento tradicional, pois, nesse contexto, é evidente o desnível de poder entre o casal, fato que impede o afloramento de processos modificadores da identidade sexual da mulher numa abordagem sociocultural ${ }^{(6)}$.

As dificuldades das mulheres em conversar com seus companheiros sexuais exclusivos sobre sua sexualidade e comportamento sexual extralar, bem como em tentar proteger-se da infecção pelo HIV quando têm desconfianças sobre o comportamento de seus parceiros são motivadas pelo fato de que homens e mulheres acham dispensável o uso do preservativo em relações sexuais entre parceiros exclusivos, pois o vêem como mais adequado às relações ocasionais ou no início do relacionamento, principalmente como método anticonceptivo. Há dificuldades de negociação sobre o uso do preservativo entre a mulher e seu parceiro exclusivo ${ }^{(4)}$.

Outro fator a ser considerado é a pauperização da epidemia, no país, como outra característica da mudança do perfil da AIDS. A explicação para essa situação é o acentuado aumento de casos na população com menor grau de escolaridade. Enquanto nos anos iniciais da epidemia, os infectados com nível de escolaridade superior ou com, pelo menos, o segundo grau completo eram maioria, a inversão dessa característica tem sido notada a partir de meados da década passada ${ }^{(1)}$. 


\section{OBJETIVO}

As considerações anteriores levaram-nos a realizar o presente estudo que teve como objetivo identificar a percepção de risco de infecção pelo HIV em mulheres residentes em uma comunidade favelar da área metropolitana da cidade de São Paulo.

\section{MATERIAL E MÉTODO}

Este estudo utilizou o método qualitativo de pesquisa, tendo a etnografia como método de coleta e de análise dos dados culturais.

Esta pesquisa foi realizada com mulheres freqüentadoras de um centro comunitário localizado em uma favela, na cidade de São Paulo. As seis mulheres que aceitaram participar da coleta de dados constituíramse nas informantes do estudo.

As informantes são, portanto, moradoras da comunidade favelar, às quais prestávamos assistência prénatal, como atividade docente-assistencial, realizando consulta, orientação individual sobre cuidados com a gravidez e com o recém-nascido, e visitas domiciliárias. São mulheres que não haviam referido comportamentos de risco para o HIV.

Todas as entrevistas foram gravadas em fitas magnéticas, após obtido o consentimento da informante, e, posteriormente, transcritas e digitadas.

Este estudo foi iniciado em 1995, portanto, anteriormente à criação da Resolução 196/96, motivo pelo qual o projeto original não foi submetido à avaliação por um Comitê de Ética em Pesquisa. Pelo mesmo motivo, o Consentimento Livre e Esclarecido foi obtido de forma verbal junto às informantes, momento em que lhes eram explicitados os objetivos e a natureza do estudo, garantindo-lhes o sigilo das informações e solicitado seu consentimento em participar.

Para a coleta de dados, foram empregadas as seguintes técnicas:

- Observação participante: neste estudo, a observação participante seguiu o OPR Model - Observation, Participation, Reflection Model ${ }^{(7-8)}$ e iniciou-se pela observação do contexto. Posteriormente, com as consultas de pré-natal e as visitas domiciliárias realizadas com os alunos, tivemos oportunidade de interagir com os moradores da comunidade, oferecendo-lhes nosso trabalho junto às gestantes nela residentes, ocorrendo, nesse período, nossa participação na comunidade. Continuamos observando o contexto e as gestantes atendidas no serviço. Encontrar as mulheres em suas casas para entrevistá-las possibilitou-nos observar seu comportamento no contexto doméstico. A quarta fase do trabalho de campo, reflexão, teve como finalidade a reflexão contínua sobre os dados já coletados e sua validação.

- Entrevista: a entrevista com as informantes foi realizada com questão descritiva. Na primeira entrevista, foram feitas questões abertas para que a mulher discorresse livremente sobre os temas "saúde e AIDS". Posteriormente, em entrevistas subseqüentes, utilizamos questões semiestruturadas que favoreceram o direcionamento do tema de maior interesse dessa pesquisa. Para direcionamento dessas entrevistas, partíamos do conteúdo da(s) entrevista(s) anterior(es) de cada informante.

É relevante dizer que o informante é alguém, membro da sociedade em estudo, que pode contar ao pesquisador sobre suas próprias ações, crenças e sobre os padrões de comportamento que envolvem uma determinada cena cultural.

- Pesquisa suplementar de dados: analisamos os registros feitos nos prontuários individuais das 282 mulheres atendidas em consultas de pré-natal realizadas no centro comunitário, oportunidade em que identificamos seus dados sociodemográficos. Esse procedimento deu-nos a visão do coletivo do grupo cultural estudado, representado pelas informantes do estudo.

Para a análise dos dados coletados, adotamos o método que melhor se aplicava ao objetivo delineado para o estudo ${ }^{(9)}$.

Segundo o método de análise adotado, e, similarmente a outros métodos, os autores consideram como ponto de partida a necessidade de cuidadosas e repetidas leituras dos dados coletados, para que eles se tornem familiares ao pesquisador. Somente após a obtenção dessa familiaridade é que deve ser dada continuidade ao processo de análise.

Cabe notar que, ao proceder a análise dos dados, o pesquisador considera os relatos dos informantes e seus registros feitos durante o trabalho de campo, os quais fornecem a evidência que leva a influências na análise, com base em uma estrutura conceitual. Esse procedimento possibilita um caráter dinâmico ao fenômeno em estudo ${ }^{(10)}$.

O passo seguinte é a classificação dos relatos 
das informantes, agrupados por afinidades de conteúdo, que passam a caracterizar as categorias. Nesse momento, cada segmento dos dados deve ser revisto e ter realçada sua relevância para uma ou mais categorias em comparação aos outros segmentos igualmente categorizados.

O resultado da análise dos registros obtidos durante o trabalho de campo e do conteúdo das entrevistas foi validado junto às respondentes, evitando-se, assim, possíveis distorções que pudessem ter ocorrido na interpretação que fizemos a partir dos procedimentos de coleta e de análise dos dados.

Finalizada a análise dos dados, segundo o método etnográfico adotado, os resultados foram submetidos também à análise conforme o Modelo de Crenças em Saúde ${ }^{(11)}$. Procedemos dessa forma para melhor conhecer a motivação das mulheres daquele contexto cultural para realizar ações de saúde no seu enfrentamento da AIDS.

Segundo os autores que desenvolveram e que aplicam o Modelo adotado ${ }^{(11-12)}$, os indivíduos realizam ações para desviar, proteger ou controlar condições de saúde-doença se eles se percebem como suscetíveis a essa condição. Também agirão se acreditarem que a condição de saúde tem, potencialmente, sérias conseqüências para sua vida.

O Modelo de Crenças em Saúde adotado neste estudo analisou os resultados etnográficos obtidos segundo os seguintes componentes: suscetibilidade e seriedade percebidas pelas mulheres quanto aos riscos de infecção pelo HIV; relação que fazem entre benefícios e barreiras que influenciam a realização de determinada ação para proteger-se do vírus; motivação, que direciona sua ação para a prevenção; e auto-eficácia, que, quando presente, facilita à mulher realizar, com sucesso, ações para se proteger do HIV.

\section{RESULTADOS E COMENTÁRIOS}

Os dados foram coletados no período de agosto de 1995 a abril de 1998 e são apresentados com exemplos de trechos das entrevistas realizadas com as informantes.

A análise dos dados mostrou que as mulheres da comunidade, ao constituírem família, o fazem ainda adolescentes, estabelecendo uma união consensual com um homem de mais idade. É responsabilidade do homem manter o sustento da família, enquanto à mulher destina- se o cuidado dos filhos e os afazeres domésticos.

Para este texto foram selecionados os temas sobre AIDS, em cujos relatos as mulheres da comunidade demonstram seu temor por infectarem-se. Esse medo advém da possibilidade de o homem infectar-se pelo relacionamento sexual extralar com outra mulher. Embora esta seja uma situação possível, a maioria das mulheres nem sequer cogita a possibilidade da ocorrência do fato. A confiança depositada no companheiro permeia essa condição, havendo mesmo quem procure nem pensar a respeito.

Eu tenho muito medo, né? Apesar que ele (companheiro) também tem medo. (...) Eu tenho medo demais de eu ficar doente assim, dele pegar, de arrumar outra, sabe, outra mulher, de não saber nada e ele também saber que ele tem alguma coisa e passar pra mim. Aí eu tenho medo. Pensar em ficar com aquela coisa, né? Emagrecer, se acabar.

Vemos, pelo relato acima, que as mulheres vêem possibilidade de infectar-se pelo HIV, caso seu companheiro desconheça a condição de soropositiva da parceira que um dia possa vir a manter num relacionamento extralar. No entanto, o grau de confiança manifestado pelas mulheres em relação ao companheiro é tão elevado que elas referem não se preocupar com a possibilidade de infectarem-se pelo HIV, transmitido pela via sexual, uma vez que acreditam no relacionamento exclusivo.

A confiança no companheiro permeia todas as afirmações. Também há quem desconheça o próprio risco de infectar-se, deixando ao destino essa possibilidade.

$A h$, não porque eu confio nele.

Não se tiver que pegar. Aí agora ninguém sabe, quem é que tem risco, quem é que não tem.

As mulheres deixam evidente sua convicção de que, pela relação sexual com o parceiro, não há possibilidade de virem, um dia, a ter AIDS.

Não se ver com possibilidade de infectar-se pelo HIV por meio do relacionamento sexual com o companheiro, torna as mulheres da comunidade suscetíveis ao vírus da AIDS. As estatísticas atuais mostram o avanço dessa epidemia em mulheres de baixa renda, com família constituída e relacionamento exclusivo. No entanto, as mulheres, informantes deste estudo, acreditam que mantêm relacionamento exclusivo com seus companheiros, em quem confiam e não visualizam com comportamentos sexuais inseguros. É importante relembrar que essas mulheres atendem ao perfil da população de risco para o HIV, por fazerem parte de famílias 
com baixo grau de escolaridade e pertencerem a um segmento da população carente de recursos de informação e de tratamento de saúde.

Sua despreocupação em avaliar a própria condição diante da possibilidade de infectarem-se pelo HIV, embora considerem a AIDS uma doença letal, é um fato. A AIDS está tão distante delas, que nem chegam a comentar sobre a síndrome, com seus companheiros. Cremos que essas mulheres, membros de famílias de baixa renda, com dificuldades socioeconômicas para sobrevivência saudável, dedicam todos seus esforços à modificação dessa condição. Suas energias são dispendidas em fatores de resolução imediata no seu cotidiano, e estes ocupam todos os seus pensamentos. Como conseqüência, vêem a AIDS distante delas e, portanto, delegada a segundo plano, daí sua despreocupação com essa síndrome.

Ah, pensar eu penso, sim. (...) Pensar a gente pensa, mas preocupar assim, não, né?

Conversar com o companheiro sobre a AIDS também não faz parte da vida dessas mulheres:

Eu não. Não conversei sobre isso não.

Os dados mostram que as mulheres caminham solitárias na manutenção da própria saúde. Para as informantes, a AIDS continua distante de seu cotidiano.

Aceitar diferenças de comportamento entre o homem e a mulher faz parte da cultura brasileira que dá àquele a possibilidade de divertir-se fora de casa, sem que a mulher tenha o direito de fazer o mesmo ou de cobrar dele justificativas para esse comportamento. Para suas saídas, o homem não leva a mulher, a qual permanece cuidando dos filhos, em casa. Tal fato evidenciase nas afirmativas das mulheres deste estudo, dentre as quais destacamos a seguinte:

A mulher também não pensa assim. Se pensasse assim, acho que o homem não gostaria. (...) A mulher fica, é verdade. $A$ mulher não vai fazer o que o homem faz, né? Então. É isso que eu acho. (...) Também se (a mulher) fizer, o homem não vai querer, né? (...) A diferença que tem é que quem é casado não se diverte nada. Se diverte se quiser também. (...) Mas tem uns que já vai, quer nem saber, se é casado, se é solteiro, não é?

O homem, sair desacompanhado, deixando a família em casa, é característica desse grupo cultural. $\mathrm{O}$ homem recebe apoio social para essa atitude, enquanto da mulher é esperado que não tenha comportamento semelhante, ou seja, que não saia de casa sozinha, para se divertir.

O fato de ter constituído uma família modifica a maneira como a mulher é vista na comunidade. Ela deve permanecer cuidando da casa e dos filhos, no ambiente privado, mesmo se o companheiro tem o hábito de ausentar-se de casa para freqüentar locais de diversão. Aceitar essa situação faz parte de sua cultura.

Algumas mulheres, porém, consideram que essas saídas de seus companheiros podem prejudicar a harmonia da união, pois, com freqüência, nessas ocasiões, acreditam que o homem relaciona-se com outras mulheres.

Mas tem homem casado que..., se diverte bastante, não está nem aí. Acaba acabando o casamento. (...) (a pessoa solteira) se diverte mais que o casado. (...) Ele tava a fim de sair esses dias. Saiu, dançou, diz ele que não aprontou nada. Dançou, brincou, disse que bebeu bastante, chegou tarde em casa. (...) Eu acho que atrapalha o casamento. E outra, ninguém segura homem. $O$ meu mesmo se ele for pra sair mesmo, eu não seguro ele. (...) Tá se divertindo, tá dançando, tá lá, na lenga-lenga. É. Que nem o meu. As mulheres vão logo beijar, pra chegar em casa, o homem já brigar com a mulher. Tudo isso tem aí fora, não é?

A mulher, nessa comunidade, é destituída de qualquer poder para manter o companheiro junto à família, caso ele tenha intenção de sair para divertir-se.

A possibilidade de o companheiro infectar-se com alguma doença transmissível é real. As mulheres vêem o companheiro como o responsável pela sua saúde. Depositam em seu comportamento extralar a manutenção da saúde de ambos. Diante da possibilidade de um relacionamento extralar do companheiro, as mulheres acreditam que sua(s) parceira(s) nem sempre é saudável e, caso esteja infectada pelo HIV, há grande possibilidade de o homem infectar-se durante relacionamento sexual. A conseqüência lógica dessa situação é a transmissão do vírus a sua mulher, dentro de casa.

Ah, sei lá! O negócio da AIDS é mais assim, fora, né? Não é assim, fora? Que nem a pessoa vai... sai com a pessoa fora, já tá contaminada, da AIDS. Fora de casa. Fora de casa, né. Eu acho assim. Eu acho que dentro de casa, assim, eu acho que não. Que nem eu tenho meu marido. Se ele sai fora com uma mulher, e a mulher tá com AIDS, vai pegar, não vai? Vai trazer pra dentro de casa. Eu penso assim. (...) Sair com mulher fora, mulher de zona, assim, eu acho que ele pega AIDS, aí ele traz pra dentro de casa e pega na mulher.

Ah, sei lá, eu? Assim, freqüentando ambiente badalado, conhecendo essas menininhas zoeira. Menininha que gosta de sair com um e com outro. Aí eles vai, confia nelas, sai com elas, pega, transmite doença pra dentro de casa, pra família. Eu acho assim.

Os dados mostram também que as mulheres 
acreditam na palavra do companheiro e, porque a eles são fiéis, esperam que seus maridos lhes contem se estiverem mantendo uma relação extralar com alguém. Somente assim, passarão a utilizar preservativo masculino durante relacionamento sexual, a fim de protegerem-se da transmissão do HIV, pois consideram que, nem sempre, a sorologia de uma pessoa é conhecida, nesse caso, da parceira de seu companheiro.

Porque eu acho que os maridos deviam ser assim. Se chegar um tempo de eles, nem que não seja doente uma mulher, que ninguém sabe. Essas coisas ninguém sabe, ninguém prevê. Eles chegar um tempo e arrumar uma mulher fora de casa, ele devia chegar pra sua mulher e falar, ou então, mesmo sem ela saber, de fazer um exame, porque não é nada demais isso. Pelo menos se ele não quer prevenir a saúde dele, ele devia prevenir a saúde da sua mulher. Eu, na minha visão, eu acho isso.

Às vezes eu converso com meu marido, falo pra ele que o dia que ele arrumar uma mulher fora de casa, ou ele fale pra mim, pra mim me prevenir, ou então ele mesmo chegue no hospital, ou vá fazer um exame pra ele mesmo se prevenir.

As mulheres depositam confiança no comportamento do companheiro, o que as faz acreditarem que ele se submeterá ao teste anti-HIV, caso venha a manter uma relação extralar. Essa medida preveniria a companheira da transmissão do vírus da AIDS, pois seu parceiro manteria seu controle sorológico, ainda que dela escondesse o fato.

Um dado que chama a atenção ao discutir o conteúdo dos relatos das mulheres é a não abordagem dos temas sobre homossexualismo e uso de drogas injetáveis. As mulheres admitem a possibilidade de um relacionamento sexual extralar de seus companheiros, porém, realizados com outra(s) mulher(es). Outro fator a considerar é o tempo passado. Nenhuma mulher referiuse ao comportamento de seus companheiros, no passado, que pudesse tê-los exposto aos riscos de infectar-se pelo HIV. Elas falam do presente e do futuro e, nesse tempo, não há possibilidade de desenvolvimento da AIDS entre o casal.

Cabe lembrar que a AIDS leva alguns anos para manifestar-se no indivíduo infectado e, na maioria dos casos, o portador desconhece sua condição por longo tempo. O período em que o vírus permanece desconhecido em seu organismo, na maioria dos casos, coincide com a fase reprodutiva ativa do indivíduo que pode ter transmitido o HIV a sua(s) parceira(s), infectando-a(s). Essa constatação reforça os dados já identificados na década passada $^{(13)}$.
Por outro lado, o desconhecimento das mulheres sobre as preferências sexuais do homem com o qual compartilham uma união estável, pode expô-las ao risco de infectarem-se com o HIV, dentro de casa. Ressalte-se que, em estudo realizado com travestis na cidade de São Paulo, verificou-se que a maioria da clientela da amostra era de bissexuais masculinos, muitas vezes casados ${ }^{(14)}$.

A quebra de fidelidade entre um casal gera brigas e a possibilidade de uma união desfeita, pois as mulheres dessa comunidade relatam a intenção de separarem-se de seus companheiros, caso eles se envolvam com outra mulher ou lhes transmitam doenças.

Falo pra ele que o dia que eu souber que ele fez alguma coisa errada, assim. Ou acontecer alguma coisa comigo que eu pegar dele. Ele tem que sumir da minha vida. Pegar essas doença. (...) Nunca tive ninguém além dele e eu penso que, depois que ele ficou comigo, ele nunca ficou com ninguém também. Eu penso, né? A gente não sabe. (...) É ele sair com outra mulher. Apesar que ele fala que nunca vai fazer isso. Agora nós não estamos morando junto... mas, se, depois, por acaso, nós voltar e tudo e ele tiver saído com outra, eu não vou aceitar, mesmo que nós estava separado, já. Aí eu não aceito.

As mulheres não aceitam a possibilidade de adoecerem como conseqüência da quebra de fidelidade de seu parceiro. Preferem desfazer a união, caso ele venha a manter relacionamento extralar com alguém.

\section{CONCLUSÃO}

Acreditamos que a dupla situação vivenciada pelas mulheres - espera do comunicado de uma relação extraconjugal do companheiro, e a intenção de desfazer a união, caso venha a ter conhecimento dessa relação gera maior risco para as mulheres da comunidade onde este estudo foi realizado. Fazemos essa afirmação porque, se a confiança depositada na lealdade do companheiro associa-se à não utilização de prevenção em suas relações, e esta é condicionada à informação sobre a existência de outra mulher, o risco de infectar-se com o HIV é real, caso o homem, sob a ameaça de rompimento da união, mantiver a parceira ignorando sua relação extralar, expondo-a, portanto, ao risco que desconhece.

Outro fator a considerar é a possível omissão do parceiro sobre sua situação de soropositivo, gerando a transmissão do HIV para sua companheira que segue desconhecendo sua condição de infectada. Os fatores 
envolvidos nesse caso embasam-se na relação do casal que sofre abalo na confiabilidade mútua diante da constatação da infidelidade de um dos parceiros. Informar sobre a sorologia positiva para o HIV implica a revisão dos laços de união e de confiança entre o casal.

Conforme o Modelo de Crenças em Saúde, as mulheres da comunidade, embora não reconheçam o fato, demonstram elevada suscetibilidade para a infecção pelo HIV, uma vez que não adotam medidas preventivas da transmissão sexual do vírus. Reconhecem, igualmente, a severidade da doença, caso venham a infectar-se, porém têm baixa motivação para agir diante da relação entre os benefícios que percebem em manter-se saudáveis e as barreiras que terão de enfrentar para proteger-se junto a seus companheiros. Igualmente reduzida é a percepção de auto-eficácia dessas mulheres, diante da possibilidade de infectarem-se com o HIV.

Concluíndo, os dados mostraram que a responsabilidade do homem sobre a saúde da família é o suporte da confiança nele depositada pela mulher. Ao homem, único membro da família que se diverte extralar, reside o papel protetor da saúde da mulher e dos filhos, já que a manutenção do equilíbrio da relação entre saúde-

\section{REFERÊNCIAS BIBLIOGRÁFICAS}

1. Castilho EA, Szwarcwald CL. Situação da AIDS no Brasil. Diagn Tratamento 1997; 2(3):17-20.

2. Barbosa RM, Villela WV. A trajetória feminina da AIDS. In: Parker R, Galvão J, organizadores. Quebrando o silêncio: mulheres e AIDS no Brasil. Rio de Janeiro (RJ): RelumeDumará; 1996. p.17-32.

3. Boletim Epidemiológico AIDS 2001 [citado 2001, Set]; Disponível em URL: http://www.aids.gov.br.

4. Guimarães K. Nas raízes do silêncio: a representação cultural da sexualidade feminina e a prevenção do HIV/AIDS. In: Parker R, Galvão J, organizadores. Quebrando o silêncio: mulheres e AIDS no Brasil. Rio de Janeiro (RJ): RelumeDumará; 1996. p.89-113.

5. Bastos C, Galvão J, Pedrosa JS, Parker R. Introdução. In: Parker R, Bastos C, Galvão J, Pedrosa JS. A AIDS no Brasil: 1982-1992. Rio de Janeiro (RJ): Relume-Dumará; 1994. p.13-56.

6. Barbosa RM. Feminino e AIDS. In: Parker R, Galvão J, organizadores. Quebrando o silêncio: mulheres e AIDS no Brasil. Rio de Janeiro (RJ): Relume-Dumará; 1996. p.153-68.

7. Leininger MM. Ethnomethods: the philosophic and epistemic bases to explicate transcultural nursing knowledge. J Transcult Nurs 1990; 1(2):40-51.
AIDS, no contexto familiar, dependerá de seu comportamento. As mulheres têm a esperança de que seus companheiros sejam suficientemente leais ao contarIhes sobre uma possível infecção pelo HIV, a fim de que possam manter sua saúde. Os traços culturais identificados mostram a necessidade do envolvimento do casal em programas de prevenção da infecção pelo vírus da AIDS.

\section{CONSIDERAÇÕES FINAIS}

A interpretação feita pelas mulheres da comunidade quanto a sua suscetibilidade para infectar-se com o HIV, no que respeita a acreditar no senso de responsabilidade do companheiro, ao comunicar-lhe uma relação extralar ou um resultado positivo para o teste antiHIV, caracteriza esse grupo cultural.

Nossa percepção sobre a constatação acima identifica a necessidade de medidas preventivas de transmissão do HIV, a serem adotadas pelo casal, conjuntamente, pois, nas reações do parceiro, reside a maior barreira da mulher para proteger-se do vírus da AIDS.

8. Leininger MM. Ethnonursing: a research method with enables to study the theory of culture care. In: Leininger MM. Culture care diversity and universality: a theory of nursing. New York: National League for Nursing Press; 1991. p.73-117.

9. Hammersley M, Atkinson P. Ethnography: principles in practice. London: Routledge; 1990.

10. Mackenzie AE. Evaluating ethnography: considerations for analysis. J Adv Nurs 1994; 19(4):774-81.

11. Rosenstock IM. Historical origins of the health belief model. Health Educ Monogr 1974; 20(4):328-35.

12. Rosenstock IM, Strecher VJ, Becker MH. The health belief model and HIV risk behavior change. In: Diclemente RJ, Peterson JL. Preventing AIDS: theories and methods of behavioral interventions. New York: Plenun Press; 1994. p.5-24.

13. Santos NJS. A AIDS entre as mulheres no Estado de São Paulo. In: Parker R, Galvão J, organizadores. Quebrando o silêncio: mulheres e AIDS no Brasil. Rio de Janeiro (RJ): Relume-Dumará; 1996. p.33-59.

14. Grandi JL. Infecção por HIV e sífilis: estudo comparativo entre a prostituição viril e travestida na cidade de São Paulo. [Dissertação]. São Paulo (SP): Escola de Enfermagem/USP; 1996. 